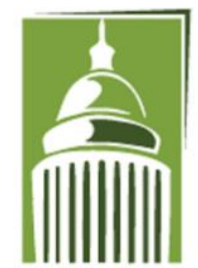

AR F

\section{Global Proceedings Repository \\ American Research Foundation}

ISSN 2476-017X

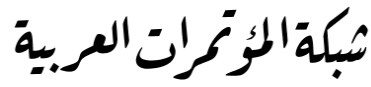

http://arab.kmshare.net/

Available online at http://proceedings.sriweb.org

The 10th International Scientific Conference

Under the Title

"Geophysical, Social, Human and Natural Challenges in a Changing Environment"

$$
\begin{aligned}
& \text { المؤتمر العلمي الدولي العاشر } \\
& \text { تحت عنوان "التحديات الجيوفيزيائية والاجتماعية والانسانية والطبيعية في بيئة متغيرة" } \\
& 25 \text { - } 26 \text { يوليو - تموز } 2019 \text { - اسطنبول - تركيا }
\end{aligned}
$$

http://kmshare.net/isac2019/

\title{
Job satisfaction among Nurses working at three teaching Hospitals in Erbil City
}

\author{
Zhyan A. Esmael $^{\mathrm{a}}$, Namir G. Al- Tawil ${ }^{\mathrm{b}}$, Tiran J. Piro \\ ${ }^{a}$ HM University, College of Nursing and Midwifery.,Iraq, Erbil \\ zhyan.ismael@hmu.edu.krd \\ ${ }^{\mathrm{b}}$ HM University, College of Medicine., Iraq, Erbil \\ namir.altawil@med.hmu.edu.krd \\ ${ }^{\mathrm{c}}$ HM University, College of Nursing and Midwifery.,Iraq, Erbil \\ tirandarvan@yahoo.com
}

\begin{abstract}
The aim of the study was to assess job satisfaction among nurses working provided in Rizgary teaching hospital, Hawler Teaching Hospital and the Maternity Teaching Hospital in Erbil city, and to find out the factors that are associated with the high level of satisfaction. A cross-sectional study was conducted in Rizgary Teaching Hospital, Hawler Teaching Hospital and the Maternity Teaching Hospital in Erbil city starting from May 1, 2017, to Jan 31, 2018.
\end{abstract}




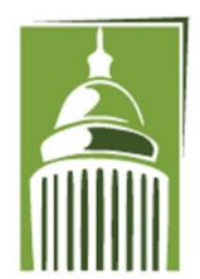

ARF

\section{Global Proceedings Repository \\ American Research Foundation}

ISSN 2476-017X

Available online at http://proceedings.sriweb.org

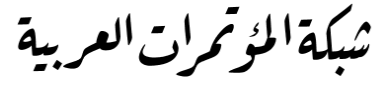

http://arab.kmshare.net/

A convenience method of sampling was used to recruit 150 nurses from the medical and surgical wards. The Conclution he level of job satisfaction among nurses caring for adults in Erbil is moderate, but the data suggest that this can be magnificently increased if the nursing practice environment is improved.

Keywords: job satisfaction, wards, nurse's work, opinion, medical, surgical.

\section{Introduction}

Job satisfaction was defined as the degree to which employees like or enjoy their jobs (Mrayyan, 2007). Job satisfaction is one of the most important subjective aspects in which work and its conditions are reflected in the context of individual norms, value orientation, aspirations and expectations ( Kožuchová, 2015). Job satisfaction is a significant predictor of the quality and efficiency of the health-care systems (Dixit and Sharma, 2017).

Nurse Job satisfaction is a multidimensional phenomenon that is influenced by many variables. Autonomy has been identified as the strongest predictor of nurse job satisfaction, which in turn reflects positively on nurse retention (Boyle, 1999).

Job satisfaction is an important predictor of an individual's intention to leave the workplace. It is increasingly being used to consider the retention of health workers in low-income countries. However, the determinants of job satisfaction vary in different contexts, and it is important to use measurement methods that are contextually appropriate (Batura et al, 2016).

A study conducted by (Pietersen, 2005) revealed that $44 \%$ of the respondents were satisfied with their working conditions at a government hospital located in Capricorn District of the Limpopo Province, South Africa. A more detailed analysis showed that the majority felt that the working was unpleasant $(61 \%)$. Overall, most of the nursing staff $(63 \%)$ was dissatisfied with their supervisors. The majority $(61 \%)$ of respondents were unhappy with pay. However, most of them $(73 \%)$ did not felt insecure and felt that the organization had enough resources to pay their salaries. Only $49 \%$ of the respondents were satisfied with their organization.

Two studies had been conducted in Erbil teaching hospitals regarding nurses' job satisfaction (Ali et al, 2014; Al-Doski et al, 2010).

Another study conducted by (Mahmoudi et al, 2016) in Rizgary teaching hospital in Erbil city in Iraq showed that $27.7 \%$ of nurses were satisfied with their orientation period to the the hospital when they have been working for less than one year. $44.4 \%$ of nurses were satisfied with their supervisor or leader. Factors found to have a negative impact on job satisfaction were salary (58.5\%), patient and family attitude $(41.1 \%)$, shift and working hours (40\%), and lack of support from management $52.3 \%$ ).

The objectives of this study were to assess the level of job satisfaction among nurses working in medical and surgical wards in Erbil city/ and to find out the factors influencing job satisfaction including the demographic variables of the nurses.

\section{Subjects and methods:}

A cross-sectional study was conducted in Rizgary Teaching Hospital, Hawler Teaching Hospital and the Maternity Teaching Hospital in Erbil city starting from May 1, 2017, to Jan 31, 2018. 


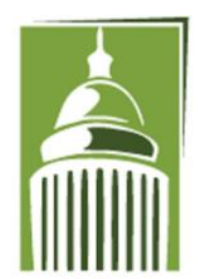

ARF

\section{Global Proceedings Repository \\ American Research Foundation}

ISSN 2476-017X

Available online at http://proceedings.sriweb.org

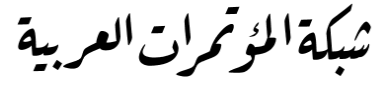

http://arab.kmshare.net/

A convenience method of sampling was used to recruit 150 nurses from medical and surgical wards. Nurses who were available in the mentioned hospitals during the presence of the researcher had been included in the study.

A self-administered questionnaire "Job Satisfaction Survey" (JSS) which was developed by Paul Spector (Spector, 1985) was used to collect the data after doing modifications to the mentioned questionnaire. The questionnaire consisted of two parts; part one related to socio-demographic characteristics of nurses (such as age, gender, marital status, levels of education, duration of services and levels of income). Part two involved a number of questions about nurses' job satisfaction. Five points Likert scale was used to assess nurses' satisfaction, where score four indicates the highest level of satisfaction and score zero indicates no satisfaction at all. Accordingly, the maximum score was 100 (4 scores X 25 questions). Scores higher than the median had been classified, in general, as satisfied.

Scores zero and one were combined into one category indicating a low level of satisfaction with a specified area of work, score 2 for equivocal answers, and scores three and four had been combined also, indicating satisfaction with a specified area of work. These combinations were used for simplicity of data presentation and data analysis.

Nurses (nursing assistants, staff nurses, and registered nurses) working at medical and surgical wards in the three main teaching hospitals in Erbil city, who were present during the period of data collection were included in the study. Those who were not willing to participate/ were excluded from the study.

Ethical approval was obtained from the Ethics Committee at the College of Nursing / Hawler Medical University. Before collecting the data, the official permission was obtained from the dean of the College of Nursing for approval to carry out the study in three teaching hospitals in Erbil city. Furthermore, permission was taken from the Erbil directorate of health in order to carry out the research in the three hospitals that are related to it.

The Statistical Package for Social Sciences (SPSS, version 22) was used for data entry and analysis. Chisquare test of association was used to compare proportions. Fisher's exact test was used (instead of Chisquare test) when the expected count of more than $20 \%$ of the cells of the tables was less than 5. A p-value of $\leq 0.05$ was considered as statistically significant.

\section{Results:}

The total number of nurses was 150 ; their mean age $( \pm \mathrm{SD})$ was $34.5 \pm 9.45$ years, ranging from $20-61$ years. The median was 33 years.

Table 1 shows that $38.7 \%$ of the study sample aged between $30-39$ years, while $35.3 \%$ were less than 30 years old. The table shows that $34.7 \%$ was working in medical wards, while $65.3 \%$ of the nurses were working in surgical wards. Three quarters $(75.3 \%)$ of the study sample was ever-married. The same table shows that the duration of service of $43.3 \%$ of the sample was less than 10 years. Regarding income, $64 \%$ of the nurses did not have adequate income for daily living. 


\section{Global Proceedings Repository \\ American Research Foundation}

ISSN 2476-017X

Available online at http://proceedings.sriweb.org

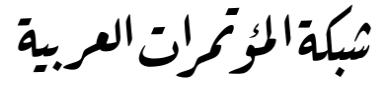

http://arab.kmshare.net/

AR F

Table 1: characteristics of the study sample.

\begin{tabular}{lcc}
\hline Variables & No. & (\%) \\
\hline Hospital & & \\
Rizgary teaching hospital & 50 & $(33.3)$ \\
Hawler teaching hospital & 50 & $(33.3)$ \\
Maternity teaching hospital & 50 & $(33.3)$ \\
Age (years) & & \\
$20-29$ & 53 & $(35.3)$ \\
$30-39$ & 58 & $(38.7)$ \\
$40-49$ & 26 & $(17.3)$ \\
$\geq 50$ & 13 & $(6.7)$ \\
Gender & & $(67.3)$ \\
Female & 101 & $(32.7)$ \\
Male & 49 & \\
Ward & & $(34.7)$ \\
Medical & 52 & $(65.3)$ \\
Surgical & 98 & $(64.0)$ \\
Level of income & & $(33.3)$ \\
Not enough & 96 & $(2.7)$ \\
Enough & 96 & $(43.3)$ \\
Duration service (years) & 50 & $(36.0)$ \\
<10 & 4 & $(20.7)$ \\
$\geq 20$ & & $(75.3)$ \\
Marital status & 65 & $(24.7)$ \\
Ever married & $\mathbf{1 0 0}$ \\
\hline Single & 54 & \\
\hline Total & 31 & \\
\hline
\end{tabular}

Table 2 shows that $82.7 \%$ of nurses were satisfied with people working with, and $66.7 \%$ enjoy their coworkers. More than two thirds (67.3\%) of the nurses claimed that they like their supervisor, $55.3 \%$ think that their supervisor is quite competent, and $34 \%$ of the nurses agreed that their supervisor was unfair to them. The same percentage (34\%) agreed that the supervisor shows little interest in the feelings of subordinates. Regarding the payment, only $9.3 \%$ were satisfied with what they receive, and the same percentage thinks that the benefits they receive are as good as other organizations offer. More than half $(59.3 \%)$ of the nurses think that their work is enjoyable, 52\% were satisfied with the chances for promotion, and $78 \%$ feel a sense of pride when they do their job.

Regarding benefits, $46 \%$ of the nurses were not satisfied with the benefits received, while $42 \%$ were satisfied. Less than half $(41.3 \%)$ had a feeling that their jobs are meaningless. 


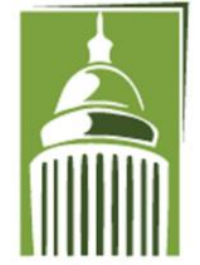

ARF

\section{Global Proceedings Repository \\ American Research Foundation}

ISSN 2476-017X

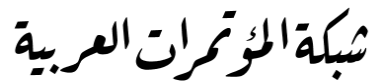

http://arab.kmshare.net/

Available online at http://proceedings.sriweb.org

Nearly half $(47.3 \%)$ of the nurses believe that rules and procedures make doing a good job difficult, and $46.7 \%$ believe that the pay raises are infrequent. Around two-thirds of nurses $(61.3 \%)$ believed that they didn't receive the benefits that they should have. Only one quarter $(25.3 \%)$ agreed that they have too much paperwork. Only $18 \%$ of the nurses agreed that there were too much bickering and fighting at work. Nearly half of the nurses (46\%) agreed that the work assignments are not fully explained.

Table 2: Distribution of sample according to levels of satisfaction with the job.

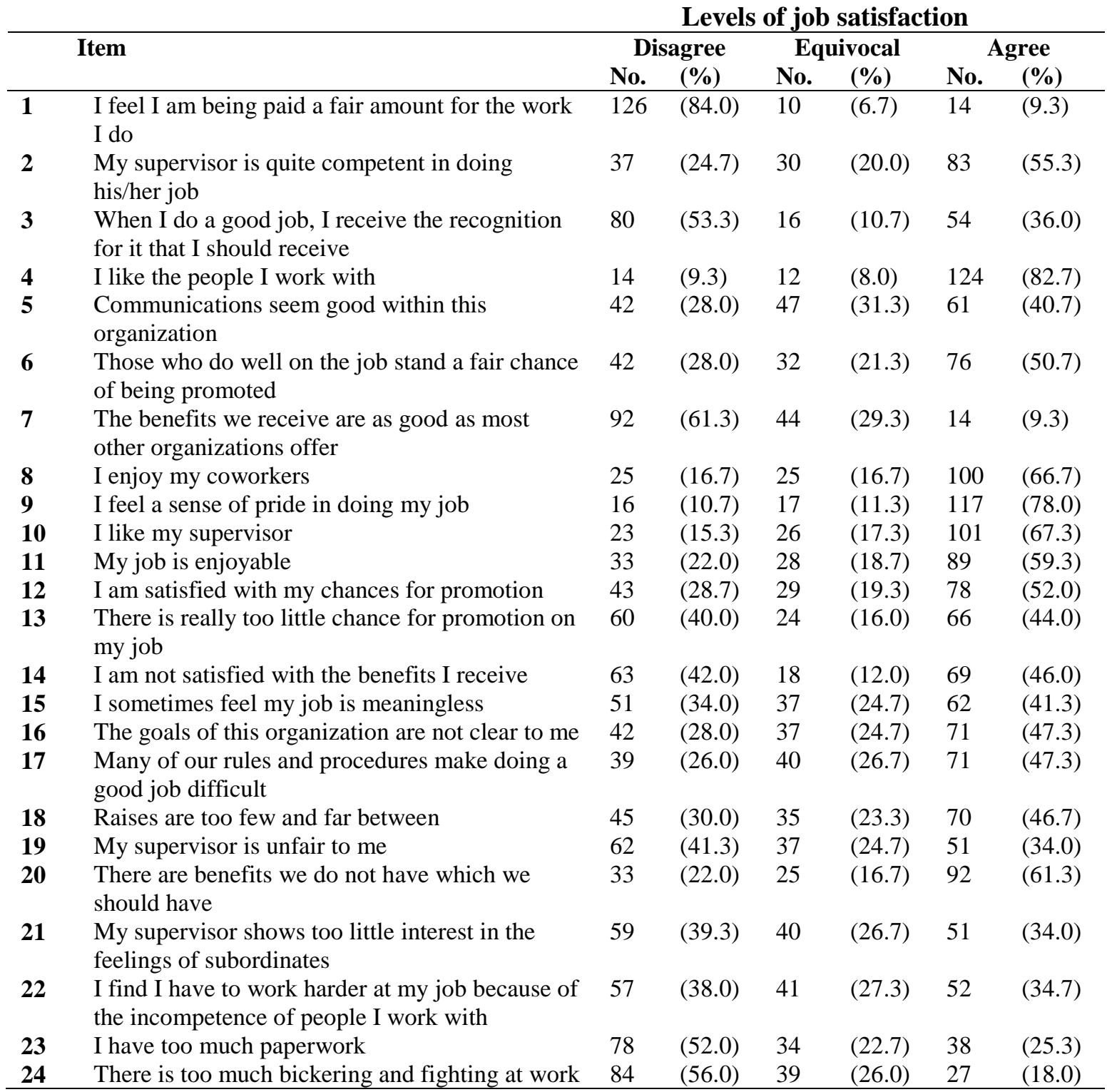




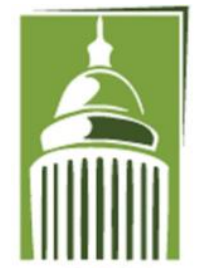

AR F

\section{Global Proceedings Repository \\ American Research Foundation}

ISSN 2476-017X

Available online at http://proceedings.sriweb.org

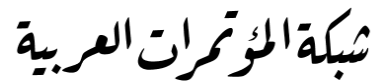

http://arab.kmshare.net/

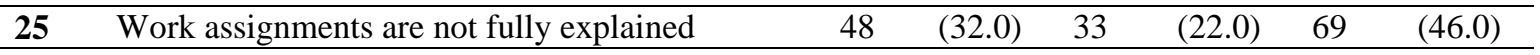

Results showed that the mean \pm SD of the satisfaction score was $52.58 \pm 10.13$, ranging from 10 to 80 out of 100. The median satisfaction score was 53. Those who scored more than the median were classified as 'satisfied'. Table 3 shows that $46 \%$ of the whole samples of the nurse were satisfied.

Table 3 shows that the highest proportion (58.5\%) of satisfaction was in the age group 20-29 years. A significant association was detected between age and the level of satisfaction. The more the age, the less the rate of satisfaction $(\mathrm{p}=0.037)$. The rate of satisfaction among females was $52.5 \%$, and that among males was $32.7 \%(\mathrm{p}=0.022)$.

A significant association was detected between the type of hospital and the level of satisfaction $(\mathrm{p}=0.043)$ where the lowest level of satisfaction was found in Hawler Teaching Hospital (32\%), compared with 56\% and 50\% in Rizgary Teaching Hospital and the Maternity Teaching Hospital respectively.

Nearly half $(48 \%)$ of nurses working in the surgical wards were satisfied with their jobs, compared with $42.3 \%$ of nurses in the medical wards $(\mathrm{p}=0.509)$.

Two thirds $(67.7 \%)$ of the single nurses were satisfied with their job compared with $38.9 \%$ of the evermarried nurses $(\mathrm{p}=0.002)$.

The majority $(75 \%)$ of the nurses with high income were satisfied, compared with $38.5 \%$ of the nurses with no enough income $(\mathrm{p}=0.028)$.

The table shows that the more the duration of service, the less the rate of satisfaction which was highest $(60 \%)$ among those with a duration of service of fewer than 10 years, lowest $(25.8 \%)$ among those who spent 20 years or more in the service $(\mathrm{p}=0.004)$. The same pattern was observed regarding the years of education. The more the years of education, the less the rate of satisfaction, but the differences were not significant $(\mathrm{p}=0.678)$.

Table 3: Level of satisfaction by basic characteristics of the studied sample

\begin{tabular}{lcccccc}
\hline Variables & N & \multicolumn{2}{c}{ Unsatisfied } & \multicolumn{2}{c}{ Satisfied } & P \\
\hline & & No. & $\%$ & No. & $\%$ & \\
\hline Age (years) & & & & & & \\
$20-29$ & 53 & 22 & $(41.5)$ & 31 & $(58.5)$ & \\
$30-39$ & 58 & 31 & $(53.4)$ & 27 & $(46.6)$ & \\
$40-49$ & 26 & 18 & $(69.2)$ & 8 & $(30.8)$ & 0.037 \\
$\geq 50$ & 13 & 10 & $(76.9)$ & 3 & $(23.1)$ & \\
Gender & 101 & 48 & $(47.5)$ & 53 & $(52.5)$ & \\
Female & 49 & 33 & $(67.3)$ & 16 & $(32.7)$ & 0.022 \\
Male & & & & & & \\
Marital status & 113 & 69 & $(61.1)$ & 44 & $(38.9)$ & \\
Ever married & 37 & 12 & $(32.4)$ & 25 & $(67.6)$ & 0.002 \\
Single & & & & & & \\
\hline
\end{tabular}




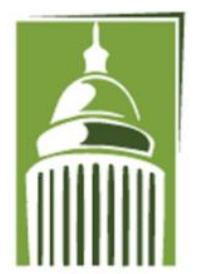

A R F

\section{Global Proceedings Repository \\ American Research Foundation}

ISSN 2476-017X

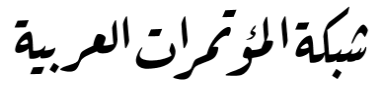

http://arab.kmshare.net/

Available online at http://proceedings.sriweb.org

\begin{tabular}{lcccccc}
\hline Level of income & & & & & & \\
Not enough & 96 & 59 & $(61.5)$ & 37 & $(38.5)$ & \\
Enough & 50 & 21 & $(42.0)$ & 29 & $(58.0)$ & $0.028^{*}$ \\
Exceeds needs & 4 & 1 & $(25.0)$ & 3 & $(75.0)$ & \\
No years of education & & & & & & \\
9 & 7 & 2 & $(28.6)$ & 5 & $(71.4)$ & \\
12 & 47 & 24 & $(51.1)$ & 23 & $(48.9)$ & \\
14 & 58 & 33 & $(56.9)$ & 25 & $(43.1)$ & \\
16 & 28 & 16 & $(57.1)$ & 12 & $(42.9)$ & 0.678 \\
18 & 10 & 6 & $(60.0)$ & 4 & $(40.0)$ & \\
\hline Total & 150 & 81 & $(54.0)$ & 69 & $(46)$ & \\
& & & & & &
\end{tabular}

*By Fisher's exact test

Table 4: Rate of satisfaction by hospital, ward, and duration of service (years) studied sample

\begin{tabular}{lcccccc}
\hline Variables & N & \multicolumn{2}{c}{ Unsatisfied } & \multicolumn{2}{c}{ Satisfied } & P \\
\hline & & No. & \% & No. & \% & \\
\hline Hospital & & & & & & \\
Rizgary teaching hospital & 50 & 22 & $(44.0)$ & 28 & $(56.0)$ & \\
Hawler teaching hospital & 50 & 34 & $(68.0)$ & 16 & $(32.0)$ & 0.043 \\
Maternity teaching hospital & 50 & 25 & $(50.0)$ & 25 & $(50.0)$ & \\
Ward & 52 & 30 & $(57.7)$ & 22 & $(42.3)$ & 0.509 \\
Medical & 98 & 51 & $(52.0)$ & 47 & $(48.0)$ & \\
Surgical & & & & & & \\
Duration service (years) & 65 & 26 & $(40.0)$ & 39 & $(60.0)$ & \\
$<10$ & 54 & 32 & $(59.3)$ & 22 & $(40.7)$ & 0.004 \\
$10-19$ & 31 & 23 & $(74.2)$ & 8 & $(25.8)$ & \\
$\geq 20$ & 150 & 81 & $(54.0)$ & 69 & $(46)$ & \\
\hline Total & & & & & & \\
\hline
\end{tabular}

\section{Discussion:}

According to the Likert scale, those who scored 3 or 4 were satisfied. Accordingly, those who got 75 out of 100 (3 scores X 25 questions) should be considered as satisfied. Actually, only one got more than 75 . In this study, those who scored more than the median were considered as 'satisfied' but in fact, they are of 


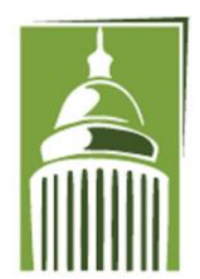

ARF

\section{Global Proceedings Repository \\ American Research Foundation}

ISSN 2476-017X

Available online at http://proceedings.sriweb.org

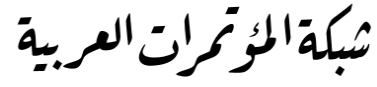

http://arab.kmshare.net/

medium satisfaction. Results showed that $46 \%$ of the nurses got scores more than the median and considered as satisfied.

A study conducted in a large metropolitan city on the East coast of the USA by (Alvarez; Fitzpatrick, 2007) showed that $67 \%$ of nurses had moderate satisfaction, $33 \%$ of the unit's nurses had low satisfaction. A study done in South Korea by (Kwak et al, 2010) showed the nurses had a higher job satisfaction rate $(68.8 \%)$. Similarly, a study done in Greece by (Nikolaou et al, 2014) showed that $38.7 \%$ of the nurses were moderately satisfied.

The result of this study reported that the majority of participants were females (67.3\%). This is consistent with the study conducted in England by (Lephalala et al, 2008) which showed that the majority of the respondents were females (92.86\%). In contrast, a study done in Ethiopia by Haile et al, 2017 showed that the majority $(57.3 \%)$ were males.

The result of this study reported that the majority of the nurses $(75.3 \%)$ had ever married. In contrast, a study done in Pakistan by (Farman et al, 2017) showed that $44.6 \%$ of participants were married. A similar study done in Lahore, Pakistan by (Dare and Ahsan-ul-Haq , 2015) showed that the majority (55\%) of the nurses were married.

In this stud, $56.7 \% \%$ of nurses have been working for more than 10 years. In contrast, a study was done in Tehran, Iran by (Eskandari; Heidari, 2018) showed that most of the nurses (77\%) had more than 10 years of experience in their jobs. A study was conducted in China to identify the nursing job satisfaction among nurses by (Zhang et al, 2013) showed that 29.3\% of nurses have been employed for more than 10 years.

The result of this study showed that $66.7 \%$ of the nurses were satisfied with their co-workers. Similar results were obtained by (Sveinsdottir et al, 2006) in Iceland who showed that nurses were most satisfied with their coworkers. A similar study done in India by (Gulavani ; Shinde, 2014) showed a high level of satisfaction (79\%) with co-workers. A study done in Jeddah by (Salem et al, 2016 ) showed that $72.9 \%$ of nurses were satisfied with their coworkers.

In this study, 53.3\% of nurses were unsatisfied with receiving recognition. In contrast to a study done India by (Gulavani and Shinde, 2014) which showed a high level of satisfaction with 'receiving recognition' $(68 \%)$.

The majority (84\%) of the nurses feel that they are not taking a fair salary. A similar study was conducted in (Slovenia by Lober and Savic, 2012) among professional nurses in Slovenian hospitals. It reported that the pay level was the second most important factor in job satisfaction. Low satisfaction with pay (salary) was also reported in Greece by (Iliopoulou and While, 2010) with income being the most common (81\%) dissatisfying factor. The study done in Jeddah by (Salem et al, 2016) showed that $40.6 \%$ of the nurses were satisfied with the pay. A similar study done in Lahore, Pakistan by (Dare and Ahsan-ul-Haq, 2015) showed that $40 \%$ were satisfied with the salary given by hospitals.

The results of the study showed that the majority of the employees (82.7\%) like the peoples who work with, 78\% feel a sense of pride in doing jobs, $67.3 \%$ like their supervisors/ and 59.3\% feel that their job is enjoyable. These results were supported by a study done by (Tasneem et al, 2018) in Pakistan which showed that the majority of the nurses were satisfied with their supervisors, nature of job and colleagues.

The results of the study showed that more than one-third of the employees were satisfied with communication $(40.7 \%)$ within the organization. In contrast, a study done in Ethiopia by (Haile et al, 2017) showed that $62.2 \%$ of nurses were satisfied with communication. A similar study done by (Tasneem et al, 2018) in Pakistan showed dissatisfaction with the factors of the communication. 


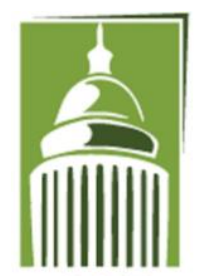

AR F

\section{Global Proceedings Repository \\ American Research Foundation}

ISSN 2476-017X

Available online at http://proceedings.sriweb.org

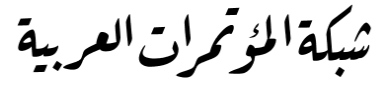

http://arab.kmshare.net/

Half $(52 \%)$ of the nurses were satisfied with the chances for promotion. In contrast, a study done by (Atefet et al, 2016) in Mashhad, Iran showed that two-thirds of the nurses (65\%) believed that opportunities for promotion were unfair and career development was not related to good performance. A study done by (Tzeng, 2002) in Taiwan showed that three quarters (76\%) of the respondents were dissatisfied with opportunities for promotion. A study done in Ethiopia by (Haile et al, 2017) showed that 63.7\% were dissatisfied with promotion opportunities.

Table 3 shows that the younger the age, the higher the rate of satisfaction. This finding coincides with the results of a study done by (Atef et al, 2016) in Mashhad, Iran, and a study done in Uganda by (Nabirye et al, 2011). This can be applied also for the duration of service, where higher rates of satisfaction were detected among those with a little duration of service who were logically younger than those with more duration of service.

The rate of satisfaction was higher among single nurses than among ever-married nurses. (Wang et al, 2015) also found in a study that had been done in China that unmarried nurses have greater job satisfaction than those who are married.

No significant association was detected between the level of education and satisfaction. In contrast, a study done in China by (Wang et al, 2015) showed that the nurses with the highest levels of education (Master's degree or above) showed greater job satisfaction than those with lower levels of education.

Among Ugandan nurses, (Nabirye et al, 2011) found that nurses reported higher levels of job satisfaction than (B.Sc Nursing) nurses. The results of the mentioned study indicated that differences in job satisfaction by the level of education among nurses were significant $(\mathrm{P}=0.002)$, and that differences in job satisfaction were related to nurses' experience; those with less experience reported higher job satisfaction than those with more experience.

\section{Conclusions:}

The level of job satisfaction among nurses caring for adults in Erbil is moderate, but the data suggest that this can be magnificently increased if the nursing practice environment is improved.

Recommendations: Further research could be conducted to find various aspects of the job that can be used to increase nurse's job satisfaction.

\section{References}

Mrayyan, M. T. (2007). Jordanian nurses' job satisfaction and intent to stay: Comparing teaching and nonteaching hospitals. Journal of Professional Nursing, 23(3), 125-136.

Kožuchová, M. V. (2015). Selected Factors Of Slovak Nurses' Job Satisfaction Central. European Journal of Nursing and Midwifery: 6 (2):260-266

Dixit, J., Goel, S., \& Sharma, V. (2017). A comparative study on the level of satisfaction among regular and contractual health-care workers in a Northern city of India. Journal of family medicine and primary care, $6(2), 416$.

Boyle, D.K., Bott, M. J., Hansen. H. E. (1999). Managers_leadership and critical care nurses_ intent to stay. American Journal of Critical Care: 8 (6): 361-371. 


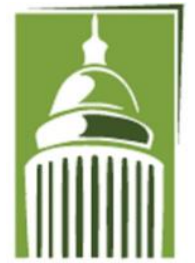

A R F

\section{Global Proceedings Repository \\ American Research Foundation}

ISSN 2476-017X

Available online at http://proceedings.sriweb.org

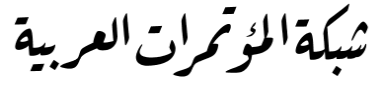

http://arab.kmshare.net/

Batura, N., Skordis-Worrall, J., Thapa, R., Basnyat, R., \& Morrison, J. (2016). Is the Job Satisfaction Survey a good tool to measure job satisfaction amongst health workers in Nepal? Results of a validation analysis. BMC health services research, 16(1), 308.

Pietersen, C. (2005). Job satisfaction of hospital nursing staff. SA Journal of Human Resource Management, 3(2), 19-25.

Ali S. K., Sabir J. M., Hussein W. A, Aziz S. h. (2014). Job satisfaction among a group of nurses in a general hospital in Erbil-city. Al kindy college medical journal. KCMJ; 10(1): 99-104

Al-Doski, S., Nazar, A., \& Aziz, K. F. (2010). JOB SATISFACTION AMONG NURSES IN IRAQERBIL CITY. International Journal of academic research, 2(5).

Mahmoudi, F., Rafii, F., Karim, M. A., \& Omer, B. O. (2016). Job Satisfaction among Nurses in Rzgary Teaching Hospital in Erbil City. kufa Journal for Nursing sciences, 6(2), 16-21.

Spector, P. E. (1985). Measurement of human service staff satisfaction: Development of the Job Satisfaction Survey. American journal of community psychology, 13(6), 693-713.

Alvarez, C. D., \& Fitzpatrick, J. J. (2007). Nurses' job satisfaction and patient falls. Asian Nursing Research, 1(2), 83-94.

Kwak, C., Chung, B. Y., Xu, Y., \& Eun-Jung, C. (2010). Relationship of job satisfaction with perceived organizational support and quality of care among South Korean nurses: A questionnaire survey. International journal of nursing studies, 47(10), 1292-1298.

Nikolaou M, Latsou D, Geitona M. (2014). Factor's influencing job satisfaction among nurses of pafos hospital in Cyprus. International society for pharmacy economic and outcomes; 17(7): 434- 438

Lephalala, R. P., Ehlers, V. J., \& Oosthuizen, M. J. (2008). Factors influencing nurses' job satisfaction in selected private hospitals in England. Curationis, 31(3), 60-69.

Haile, D., Gualu, T., Zeleke, H., \& Dessalegn, B. (2017). Job Satisfaction and Associated Factors among Nurses in East Gojjam Zone Public Hospitals Northwest Ethiopia, 2016. J Nurs Care, 6(398), 2167-1168.

Farman, A., Kousar, R., Hussain, M., Waqas, A., \& Gillani, S. A. (2017). Impact of Job Satisfaction on Quality of Care Among Nurses on the Public Hospital of Lahore, Pakistan, Saudi J. Med. Pharm. Sci. 3 (6): 511-519

Dar, I. S., \& Ahsan-ul-Haq, M. (2015). FACTORS INFLUENCING JOB SATISFACTION OF NURSES IN PUBLIC HOSPITALS. Science International, 27(3): 1761-1765 


\section{Global Proceedings Repository \\ American Research Foundation}

ISSN 2476-017X

Available online at http://proceedings.sriweb.org

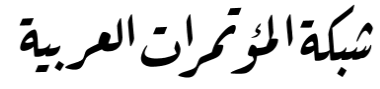

http://arab.kmshare.net/

AR F

Eskandari, M., \& Gorji, M. A. H. (2018). Can work-related stress and job satisfaction affect job commitment among nurses? A cross-sectional study. F1000Research, 1:1- 7.

Zhang, A., Tao, H., Ellenbecker, C. H., \& Liu, X. (2013). Job satisfaction in mainland C hina: comparing critical care nurses and general ward nurses. Journal of advanced nursing, 69(8), 1725-1736.

Sveinsdottir, H., Biering, P., \& Ramel, A. (2006). Occupational stress, job satisfaction, and working environment among Icelandic nurses: a cross-sectional questionnaire survey. International journal of nursing studies, 43(7), 875-889.

Gulavani, A., \& Shinde, M. (2014). Occupational stress and job satisfaction among nurses. International Journal of Science and Research (IJSR), 3(4), 733-740.

Salem, O.A., Baddar, F.M., AL-Mugatti, H.M. (2016). Relationship between Nurses Job Satisfaction and Organizational Commitment. Journal of Nursing and Health Science (IOSR-JNHS); 5 (1): 49-55

Lorber, M., \& Skela Savič, B. (2012). Job satisfaction of nurses and identifying factors of job satisfaction in Slovenian Hospitals. Croatian medical journal, 53(3), 263-270.

Iliopoulou, K. K., \& While, A. E. (2010). Professional autonomy and job satisfaction: survey of critical care nurses in mainland Greece. Journal of advanced nursing, 66(11), 2520-2531.

Tasneem, S., Cagatan, A. S., Avci, M. Z., \& Basustaoglu, A. C. (2018). Job satisfaction of health service providers working in a public tertiary care hospital of Pakistan. The Open Public Health Journal, 11(1).

Atefi, N., Abdullah, K. L., \& Wong, L. P. (2016). Job satisfaction of Malaysian registered nurses: a qualitative study. Nursing in critical care, 2l(1), 8-17.

Tzeng, H. M. (2002). Satisfying nurses on job factors they care about: A Taiwanese perspective. JONA: The Journal of Nursing Administration, 32(6), 306-309.

Nabirye, R. C., Brown, K. C., Pryor, E. R., \& Maples, E. H. (2011). Occupational stress, job satisfaction and job performance among hospital nurses in Kampala, Uganda. Journal of nursing management, 19(6), 760-768.

Wang, Y., Dong, W., Mauk, K., Li, P., Wan, J., Yang, G., ... \& Hao, M. (2015). Nurses’ practice environment and their job satisfaction: A study on nurses caring for older adults in shanghai. PloS one, 10(9), e0138035. 